\title{
Pengembangan Electronic Load Controller untuk Self-Excited Induction Generator Berbasis Penyearah Tiga Fase Menggunakan Raspberry Pi
}

\author{
Ihsan Nur Hakim ${ }^{1 *}$, Aan Listanto Amdrian', Adlan Bagus Pradana² dan \\ Awang Noor Indra Wardana ${ }^{1}$ \\ ${ }^{1}$ Departemen Teknik Nuklir dan Teknik Fisika, Fakultas Teknik, Universitas Gadjah Mada, Sleman, \\ Daerah Istimewa Yogyakarta, Indonesia \\ ${ }^{2}$ Departemen Teknik Elektro dan Informatika, Sekolah Vokasi, Universitas Gadjah Mada, Sleman, \\ Daerah Istimewa Yogyakarta, Indonesia \\ *Corresponding author, e-mail: ihsan.nurhakim97@gmail.com
}

\begin{abstract}
Abstrak - Self-excited induction generator (SEIG) dipandang tepat untuk menyuplai listrik daerah pelosok. Di samping itu, sistem kontrol terdistribusi dan modular semakin dibutuhkan untuk mengurangi biaya dan mewujudkan system otomasi yang fleksibel. Penelitian ini dilakukan untuk merintis suatu electronic load controller (ELC) dengan Raspberry Pi untuk meregulasikan frekuensi keluaran SEIG akibat perubahan beban resistif agar sesuai dengan standar frekuensi listrik Indonesia. Raspberry Pi dipilih karena memiliki potensi pengembangan tren sistem terdistribusi yang didukung oleh Framework for Distributed Industrial Automation and Control (4DIAC). Perancangan ELC dilakukan berdasarkan identifikasi karakteristik SEIG dan standar sistem listrik Indonesia. Rancangan ELC diimplementasikan dan diidentifikasi karakteristiknya. Keluaran SEIG diregulasikan pada frekuensi $50 \mathrm{~Hz}$ dan tegangan terminal nominal 294 V. Sensor yang dirancang adalah sensor tegangan dengan transformator, filter, penyearah, dan ADC. Aktuator yang dirancang terdiri dari penyearah tiga fase, beban palsu, driver optocoupler, dan IGBT. Kendali PI berbasis Python diterapkan pada Raspberry Pi Zero dengan nilai $K_{p}$ dan $K_{i}$ hasil tuning eksperimental masing-masing sebesar 5,0. Hasil uji ELC menunjukkan bahwa perubahan keluaran SEIG akibat perubahan beban dapat diregulasikan menuju standar frekuensi listrik Indonesia pada keadaan tunaknya. Simpangan terjauh SEIG dari tegangan nominal bernilai $-12,24 \%$, sementara simpangan frekuensi terbesar bernilai $+3,2 \%$, serta durasi pemulihan terlama sebesar $832 \mathrm{~ms}$.
\end{abstract}

Kata Kunci : generator induksi, pengendali beban elektronis dan Raspberry Pi.

\begin{abstract}
A self-excited induction generator (SEIG) could provide electricity for isolated areas appropriately. Besides that, distributed and modular control systems is needed to reduce the cost while creating flexible automation system. This research is conducted to design an electronic load controller (ELC) with Raspberry Pi to regulate frequency output of SEIG caused by resistive load changing to comply with Indonesian electricity frequency standard, while able to support distributed system trend with Framework for Distributed Industrial Automation and Control (4DIAC) in the future. The ELC design is based on the characteristics of SEIG and Indonesian electricity system standards. The design is then implemented, and the characteristics are identified. The output of SEIG is regulated at frequency of $50 \mathrm{~Hz}$ and terminal voltage of $294 \mathrm{~V}$. A voltage sensor is designed with a transformer, filters, rectifier, and ADC. The actuator consisted of a three-phase rectifier, dump load, optocoupler driver, and IGBT. A PI-controller based on Python is applied in Raspberry Pi Zero with experimentally tuned $K_{p}$ and $K_{i}$ values both of 5.0. The output changing of SEIG caused by resistive load changing could be regulated within the Indonesian electricity frequency standard in its steady state. The maximum voltage deviation from the nominal value is $-12.24 \%$, while the maximum frequency deviation is $+3.2 \%$, and the longest recovery time is $832 \mathrm{~ms}$.
\end{abstract}

Keywords : induction generator, electronic load controller and Raspberry Pi.

\section{Pendahuluan}

Micro-grid dapat digunakan untuk meningkatkan elektrifikasi pada daerah-daerah yang mengalami kesulitan akses geografis, khususnya di Indonesia [1]. Agar dapat beroperasi, micro-grid memerlukan komponen utama berupa generator. Self-excited Induction
Generator (SEIG) merupakan generator yang cocok untuk daerah berkesulitan akses geografis. Hal ini dikarenakan SEIG dapat dioperasikan dengan baik dan aman tanpa banyak campur tangan manusia [2].

Tegangan dan frekuensi keluaran SEIG dipengaruhi oleh kecepatan penggerak mula, 
suplai daya reaktif, dan besar beban yang disuplai [2]. Frekuensi yang berubah-ubah serta tegangan keluaran yang tak seimbang dapat mempersingkat usia generator. Agar perubahan tegangan dan frekuensi SEIG dapat bernilai konstan seiring berubahnya besar beban, maka perlu dilakukan kontrol. Dari beberapa kontrol yang ada, kontrol elektronis lebih disukai karena berbiaya relatif rendah serta memiliki performa respon dinamis yang baik. Electronic load controller (ELC) dengan chopper adalah salah satu jenis dari kontrol elektronis tersebut [3].

Di sisi lain, suatu sistem kendali yang terdistribusi dan modular semakin dibutuhkan. Hal tersebut bertujuan untuk mewujudkan sistem otomasi yang fleksibel dan berbiaya teknis rendah. Salah satu rintisan environment otomasi bersumber terbuka adalah Framework for Distributed Industial Automation (4DIAC) [4]. Salah satu perangkat kontrol yang mendukung 4DIAC adalah komputer mikro Raspberry Pi [5]. Raspberry Pi dengan adanya fitur Pulse-Width Modulation (PWM) dapat sekaligus digunakan sebagai pengendali ELC berbasis chopper untuk SEIG $[6,7]$.

Saat ini belum tersedia ELC berbasis Raspberry $\mathrm{Pi}$ yang dapat digunakan untuk meregulasikan frekuensi keluaran SEIG akibat perubahan beban resistif sesuai dengan standar kelistrikan Indonesia. Maka dari itu, penelitian ini dilakukan untuk merintis suatu ELC berbasis Raspberry Pi yang dapat meregulasikan frekuensi keluaran SEIG agar tetap memenuhi standar kelistrikan Indonesia pada keadaan tunaknya ketika mengalami perubahan beban resistif.

\section{Metoda}

Perancangan ELC untuk SEIG dengan Raspberry Pi dilakukan dalam beberapa tahap sebagai berikut.

\subsection{Identifikasi Susunan Kerja dan Karakteristik SEIG}

Perancangan ELC dilakukan dengan mengidentifikasi susunan kerja SEIG yang optimal beserta karakteristiknya. Karakteristik yang dianalisis adalah rentang tegangan dan frekuensi keluaran SEIG terkait dengan jumlah beban $\left(G_{t}\right)$ yang disuplai olehnya. Karakteristik tersebut diperlukan untuk menentukan komponen yang tepat untuk mengendalikan SEIG sesuai sistem listrik Indonesia. Alat ukur tegangan RMS
SEIG $\left(V_{g}\right)$ adalah multimeter analog Heles UX960TR, sementara alat ukur frekuensi ( $f$ ) SEIG adalah 3-phase energy analyzer Feedback 68100. Untuk memprediksi titik pengendalian SEIG, digunakan model berdasarkan regresi dengan bantuan perangkat lunak LibreOffice Calc untuk mencocokkan kurva korelasi antara konduktansi beban terhadap tegangan dan frekuensi SEIG $[8,9]$.

Karakteristik lain yang dianalisis adalah konstanta waktu SEIG $\left(\tau_{g}\right)$ ketika diberi perubahan beban resistif. Nilai $\tau_{g}$ diperlukan untuk mengetahui waktu tanggap ideal bagi ELC untuk mengembalikan keluaran SEIG menuju standar sistem listrik Indonesia. Penentuan $\tau_{g}$ dilakukan dengan mencuplik tegangan $\mathrm{AC}$ sesaat dengan rangkaian pembagi tegangan melalui Arduino Uno. Rangkaian pencuplikan tegangan AC sesaat tersebut ditampilkan pada Gambar 1a, dengan resistor $115 \mathrm{k} \Omega$ dan $1 \mathrm{k} \Omega$ berdaya disipasi maksimal $5 \mathrm{~W}$, dan resistor $10 \mathrm{k} \Omega$ cukup bernilai $0,5 \mathrm{~W}$. Bentuk fisik rangkaian pembagi tegangan tersebut ditampilkan pada Gambar $1 \mathrm{~b}$.

Nilai puncak dari tegangan sesaat digunakan untuk mengetahui $V_{g}$. Nilai-nilai tersebut didekati dengan persamaan model berbasis metode Least Square (LS) [10] untuk mendapatkan karakteristik peralihan SEIG berupa konstanta waktu. Bentuk dasar persamaan LS tersebut dirumuskan pada Persamaan (1), dengan $J E$ adalah jumlah eror, $n$ adalah jumlah data, dan $y$ adalah suatu fungsi [11]. Nilai $J E$ dicari titik minimalnya dengan menggunakan fitur solver pada LibreOffice Calc, dengan mengubah variabel $\tau$ serta besaran tegangan.

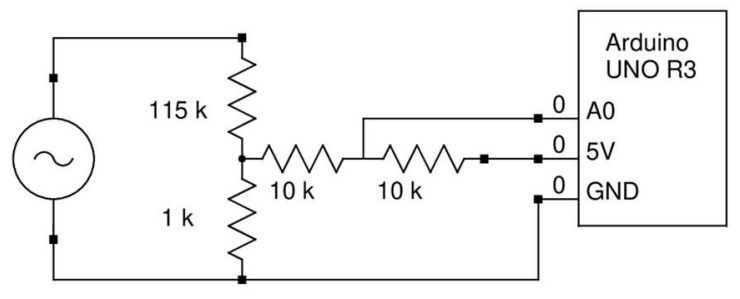

Gambar 1a. Rangkaian ukur tegangan AC sesaat SEIG dengan Arduino. 


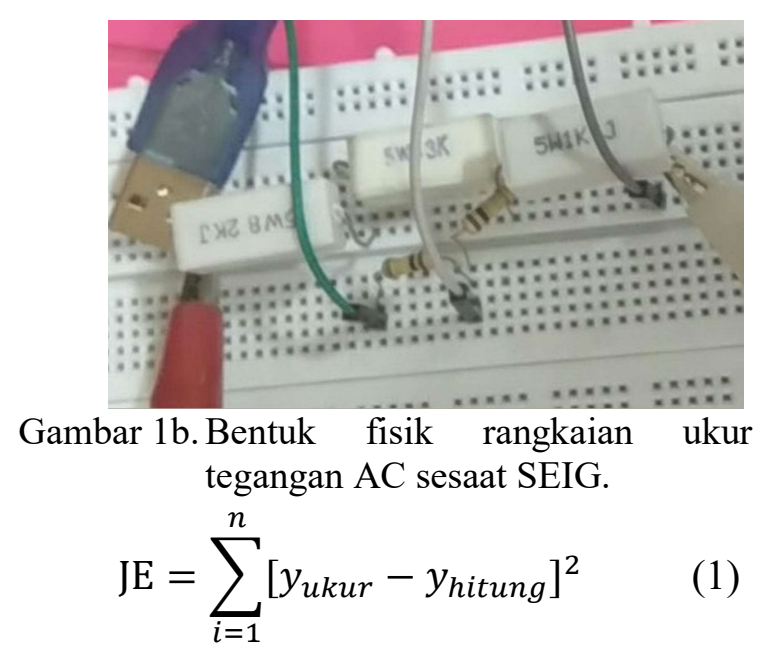

Nilai tegangan puncak sesaat yang terukur masih berupa nilai digital $\left(V_{\text {ard }}\right)$. Untuk mengetahui nilai $V_{g}$ yang direpresentasikan olehnya, digunakan Persamaan (2). Persamaan (2) didapatkan dari hasil korelasi $V_{\text {ard }}$ dengan hasil ukur $V_{g}$ pada keadaan tunak sekitar tegangan acuan.

$$
\begin{aligned}
V_{g}= & -1,46 \cdot 10^{-4} V_{A r d}^{2} \\
& +0,8691 V_{A r d}-347,2455
\end{aligned}
$$

\subsection{Identifikasi Sistem Listrik Standar Indonesia dan Titik Pengendalian SEIG}

Standar sistem listrik konsumen tegangan rendah Indonesia ditinjau untuk menentukan titik pengendalian SEIG dengan ELC. Setelah standar tersebut dikaji, titik pengendalian SEIG berupa rentang nilai konduktansi beban dapat ditentukan. Selain itu, waktu tanggap ideal SEIG setelah diberi perubahan beban juga dapat ditentukan.

\subsection{Perancangan dan Identifikasi Komponen ELC}

Komponen ELC berupa sensor, kontroler, dan aktuator dirancang dengan mempertimbangkan rentang tegangan dan frekuensi operasional SEIG serta kapasitas daya komponen penyusunnya. Algoritma kontrol disusun berdasarkan fungsi yang diperlukan untuk melakukan akuisisi data, pengendalian, dan aktuasi pada SEIG. Komponen-komponen tersebut kemudian dianalisis karakteristik keadaan tunaknya berdasarkan nilai penguatannya, sementara karakteristik peralihannya diketahui dari nilai konstanta waktunya. Karakteristik keadaan peralihan sensor dilakukan dengan cara yang serupa pada subbab 2.1, namun dengan mengumpankan langsung keluaran sensor menuju pin A0 Arduino. Karakteristik lain yang diuji adalah durasi pembacaan data oleh ADC dan eksekusi kalang kontrol. Durasi ini diketahui dengan melakukan analisis deskriptif dari sejumlah data durasi yang direkam saat eksekusi program.

\subsection{Pengujian Kinerja ELC}

Perangkat ELC yang telah dirancang dan diimplementasikan kemudian disetem secara eksperimental. Kinerja ELC diuji dengan perubahan undak beban SEIG dalam dua tahap singkat. Tanggapan peralihan SEIG berupa perubahan tegangan AC sesaat dicuplik dengan rangkaian pada subbab 2.1 dan dianalisis. Tolak ukur kinerja yang diacu adalah kemampuan ELC untuk meregulasikan keadaan tunak SEIG menuju sistem listrik standar Indonesia, simpangan terjauh tegangan dan frekuensi SEIG ketika diberi masukan undak, serta durasi pemulihan yang dibutuhkan untuk meregulasikan SEIG kembali ke nilai nominalnya. Nilai frekuensi SEIG pada uji kinerja didapatkan dari korelasi tegangan SEIG terhadap frekuensi yang telah diketahui.

\section{Hasil dan Pembahasan}

\subsection{Identifikasi Susunan Kerja dan Karakteristik SEIG}

\subsubsection{Identifikasi Susunan Kerja Optimal SEIG}

Susunan kerja SEIG dalam perancangan ini terdiri dari mesin rotor belitan $137 \mathrm{~W}$, beban resistif variabel dengan resistansi minimal 1554 $\Omega$, kapasitor variabel dengan kapasitansi minimal $16,3 \mu \mathrm{F}$, serta penggerak mula berupa motor DC compound. Pada awal operasinya, SEIG dihubungkan kepada kapasitor variabel sebesar $16,3 \mu \mathrm{F}$. Setelah mesin induksi beralih fungsi dari motor menjadi generator, kapasitansi tersebut diturunkan menjadi 7,01 $\mu \mathrm{F}$. Hal ini bertujuan untuk menurunkan tegangan keluaran SEIG serta torsi yang diperlukan untuk mengoperasikannya. Nilai kapasitansi tersebut tidak dapat diturunkan lagi, karena mesin dapat mengalami kekurangan eksitasi untuk terus beroperasi dalam keadaan aman sebagai generator. Rangkaian SEIG pada perancangan ini ditampilkan pada Gambar 2a, sedangkan bentuk fisik susunan kerja SEIG ditunjukkan pada Gambar 2b. Spesifikasi dari berbagai variabel operasional SEIG yang optimal dipaparkan pada Tabel 1. 


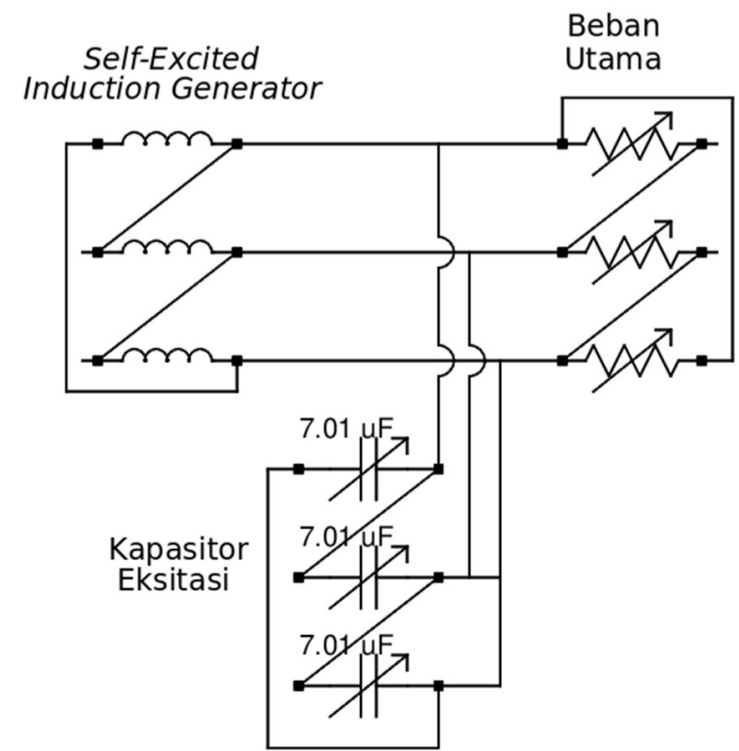

Gambar 2a. Rangkaian susunan kerja SEIG.

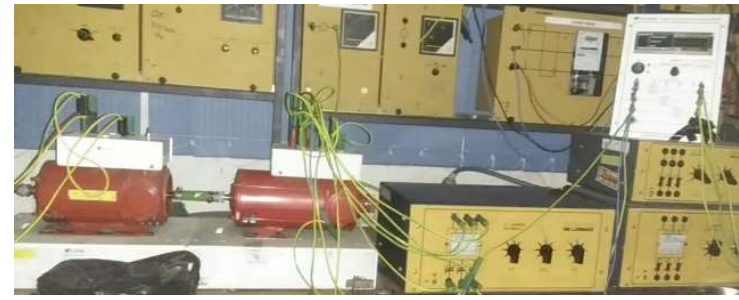

Gambar 2b. Bentuk fisik susunan kerja SEIG.

Tabel 1. Spesifikasi susunan kerja SEIG.

\begin{tabular}{|l|c|c|}
\hline \multicolumn{1}{|c|}{ Variabel } & Simbol & Nilai \\
\hline Kecepatan putar poros & $N_{g}$ & $3.290 \mathrm{RPM}$ \\
Kapasitansi eksitasi & $C_{\text {eksitasi }}$ & $7,01 \mu \mathrm{F}$ \\
Tegangan & $V_{g}$ & $292 \mathrm{~V}$ \\
Frekuensi & $f$ & $50 \mathrm{~Hz}$ \\
Jumlah beban (R) & $R_{t}$ & $1.888 \Omega$ \\
Jumlah beban $(\mathrm{G})$ & $G_{t}$ & $530 \mu \mathrm{S}$ \\
\hline
\end{tabular}

\subsubsection{Identifikasi Karakteristik Keadaan Tunak SEIG}

Setelah SEIG dioperasikan sesuai keadaan pada Tabel 1, jumlah beban dapat diubah untuk mengetahui tanggapan keadaan tunak dan peralihan dari SEIG. Jumlah beban divariasikan dan pengaruhnya terhadap keadaan tunak $V_{g}$ dirumuskan pada Persamaan (3), sedangkan grafik korelasinya ditampilkan pada Gambar 3. Sementara itu, pengaruh perubahan beban terhadap frekuensi SEIG $(f)$ dirumuskan pada Persamaan (4), dengan grafik korelasi yang ditunjukkan pada Gambar 4.

$$
V_{g}=-116.346,442 G+355,698
$$

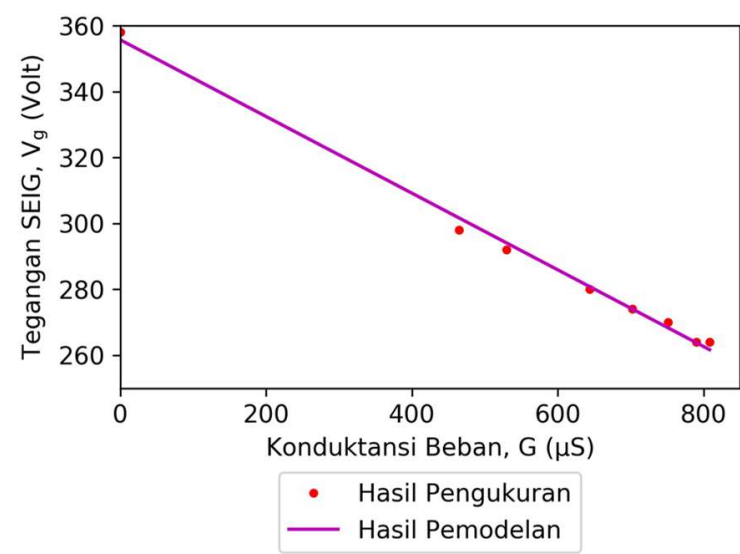

Gambar 3. Grafik korelasi konduktansi beban SEIG terhadap $V_{g}$.

$$
\begin{aligned}
f= & 4.333 .792,809 G^{2} \\
& +9643,0686 G+53,895
\end{aligned}
$$

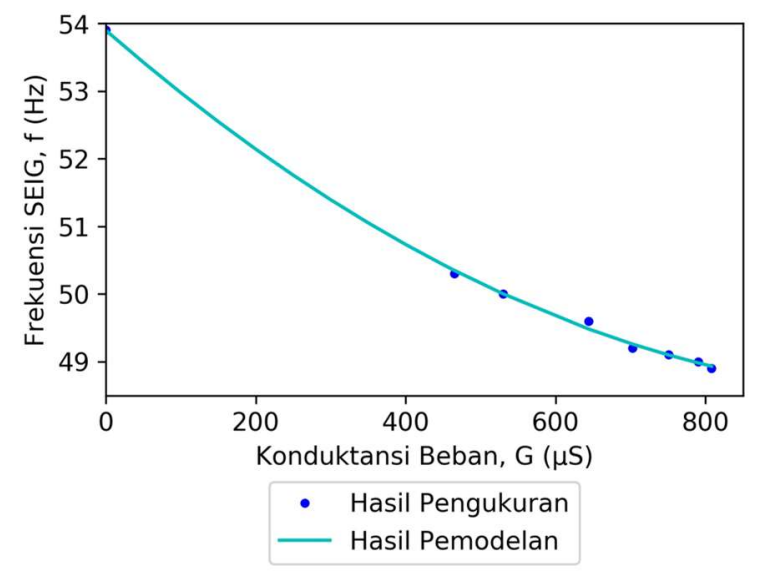

Gambar 4. Grafik korelasi konduktansi beban SEIG terhadap frekuensi keluaran SEIG.

Untuk memudahkan memprediksi nilai frekuensi SEIG tanpa menggunakan sensor khusus, digunakan korelasi nilai $V_{g}$ terhadap nilai $f$ yang bersesuaian. Korelasi ini dirumuskan dalam dua model, yaitu model polinomial $\left(f_{p}\right)$ pada Persamaan (5), serta model linear $\left(f_{l}\right)$ pada Persamaan (6). Sementara itu, grafik dari korelasi dan kedua pemodelan ini ditampilkan pada Gambar 5. Korelasi dengan model polinomial dipilih untuk memprediksi nilai frekuensi SEIG berdasarkan $V_{g}$ karena lebih representatif dibandingkan model linearnya. Hal ini ditunjukkan dari nilai koefisien determinasi $\left(R^{2}\right)$ sebesar 99,89\% untuk model polinomial, yang 
mana lebih besar dari model linearnya, yaitu $98,75 \%$.

$$
\begin{aligned}
f_{p}= & 0,00211891 V^{2} \\
& -0,078914 V+54,995 \\
f_{l}= & 0,05289 V+34,794
\end{aligned}
$$

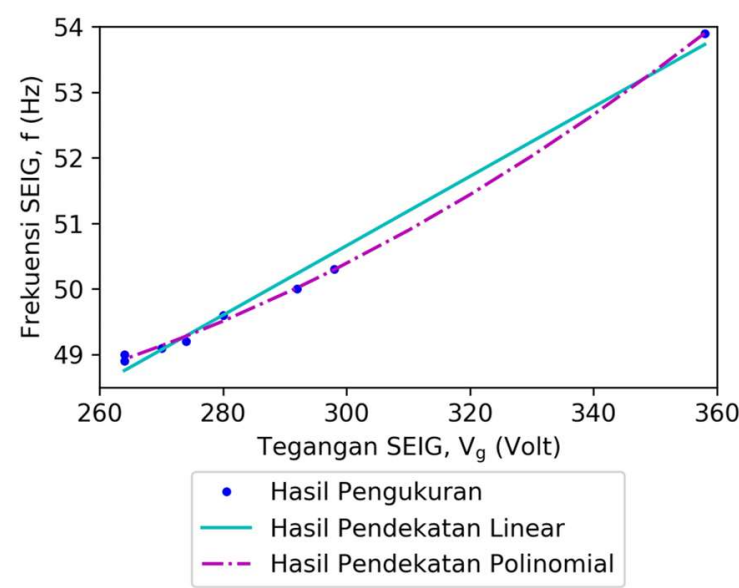

Gambar 5. Grafik korelasi $V_{g}$ terhadap frekuensi keluaran SEIG.

\subsubsection{Identifikasi Karakteristik Tanggapan Peralihan SEIG}

Karakteristik tanggapan peralihan SEIG ketika jumlah beban diubah diperlukan untuk mengetahui waktu tanggap yang ideal bagi ELC dalam meregulasikan SEIG. Dari hasil pencuplikan tegangan puncak AC SEIG menggunakan rangkaian pada Gambar 1 dan interpretasi menjadi nilai $V_{g}$ dengan Persamaan (2), dibuat suatu pendekatan model untuk mengetahui nilai $\tau_{g}$. Pendekatan model ini dirumuskan pada Persamaan (7), di mana $V_{0}, V_{l}$, dan $V_{g}$ berturut-turut adalah nilai tegangan awal, tegangan akhir, dan tegangan RMS SEIG hasil pemodelan. Agar pola grafik yang ditampilkan lebih mudah dibandingkan dengan yang lain, dilakukan normalisasi fitur dengan persamaan (8) [12] berdasarkan jenis undak naik dan turun. Normalisasi fitur ini berfungsi untuk menskala seluruh data agar nilai pemodelan tunaknya berada pada rentang 1 dan 0 .

$$
\begin{gathered}
V_{g}(t)=V_{1}+\left(V_{0}-V_{1}\right) \cdot e^{\left(\frac{-t}{\tau_{g}}\right)} \\
x_{\text {baru }}=\frac{x-x_{\text {min }}}{x_{\text {maks }}-x_{\text {min }}}
\end{gathered}
$$

Hasil pengolahan data tanggapan peralihan SEIG dijabarkan pada Tabel 2, sedangkan sampel grafik tanggapan undak menurun dan naik secara berurutan ditunjukkan pada Gambar 6a dan $6 \mathrm{~b}$.
Waktu pada grafik hasil normalisasi ditampilkan pada sumbu $x$, sementara amplitudo tegangan SEIG ditampilkan pada sumbu $y$. Dari hasil tersebut, dipilih nilai $\tau_{g}$ terlama sebesar $458 \mathrm{~ms}$ sebagai ekspektasi konstanta waktu SEIG.

Tabel 2. Konstanta waktu peralihan SEIG.

\begin{tabular}{|c|c|}
\hline Perubahan Undak $(\mu \mathrm{S})$ & $\tau_{\mathrm{g}}(\mathrm{ms})$ \\
\hline $465 \rightarrow 530$ & 387 \\
$0 \rightarrow 465$ & 231 \\
$0 \rightarrow 530$ & 360 \\
$530 \rightarrow 465$ & 458 \\
$465 \rightarrow 0$ & 443 \\
$530 \rightarrow 0$ & 376 \\
\hline
\end{tabular}

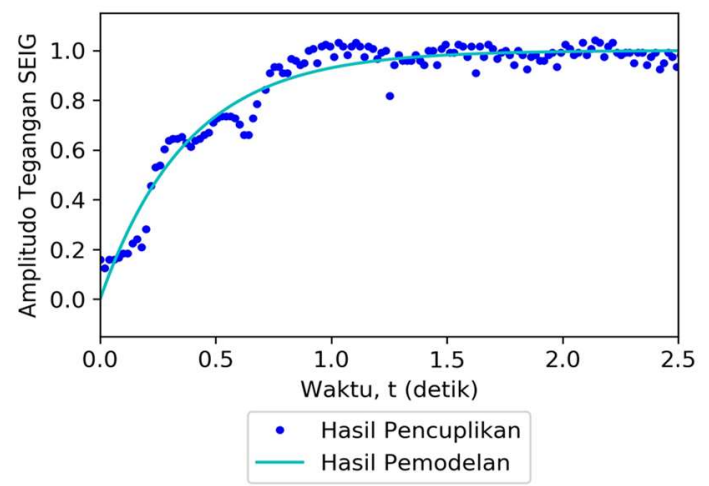

Gambar 6a. Grafik tanggapan peralihan SEIG ketika mengalami perubahan beban dari $530 \mu \mathrm{S}$ menjadi $0 \mu \mathrm{S}$.

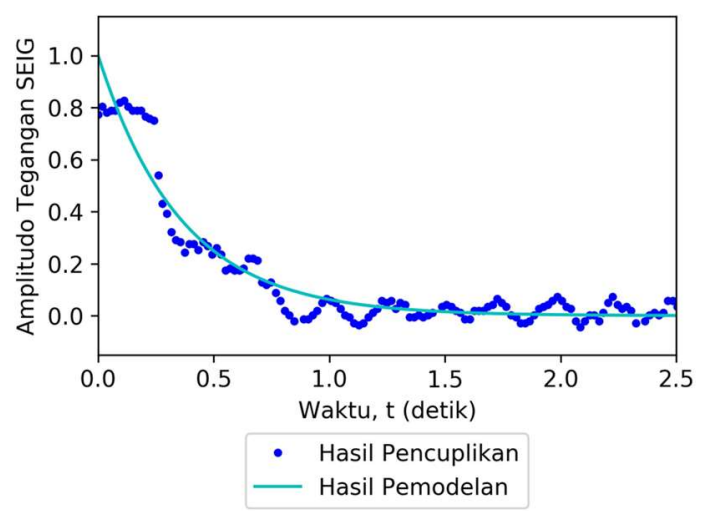

Gambar 6b. Grafik tanggapan peralihan SEIG ketika mengalami perubahan beban dari $0 \mu \mathrm{S}$ menjadi $530 \mu \mathrm{S}$. 


\subsection{Identifikasi Standar Sistem Listrik Indonesia dan Titik Pengendalian SEIG}

\subsubsection{Identifikasi Standar Sistem Listrik Konsumen Tegangan Rendah Indonesia}

Agar daya listrik yang dihasilkan oleh SEIG dapat digunakan untuk berbagai peralatan di Indonesia, daya keluaran SEIG perlu disesuaikan dengan standar sistem listrik konsumen tegangan rendah di Indonesia. Standar tersebut dipaparkan pada Tabel 3 [13].

Tabel 3. Standar sistem listrik konsumen tegangan rendah Indonesia.

\begin{tabular}{|l|c|c|c|}
\hline \multirow{2}{*}{\multicolumn{1}{|c|}{ Besaran }} & \multicolumn{3}{|c|}{ Nilai } \\
\cline { 2 - 4 } & Min & Nom & Maks \\
\hline Tegangan Beban (V) & 207 & 230 & 241,5 \\
Frekuensi (Hz) & 49,5 & 50 & 50,5 \\
\hline
\end{tabular}

\subsubsection{Identifikasi Titik Pengendalian Keluaran SEIG}

Dari Gambar 3 dan 4 dapat disimpulkan bahwa keluaran SEIG tidak bisa memenuhi standar tegangan dan frekuensi Indonesia secara bersamaan. Oleh karena itu, keluaran SEIG diregulasikan untuk memenuhi standar frekuensi listrik Indonesia. Keputusan ini dipilih karena tegangan lebih mudah dimanipulasi daripada frekuensi. Sementara itu, agar nilai tegangan keluaran SEIG tetap dapat digunakan oleh konsumen sesuai standar, diperlukan suatu penurun tegangan semisal transformator dengan rasio 294:230 yang menghubungkan antara terminal SEIG dengan terminal beban konsumen.

Titik pengendalian masukan SEIG berupa rentang konduktansi beban yang menghasilkan frekuensi SEIG pada rentang standar frekuensi listrik Indonesia ditampilkan pada Tabel 4. Nilai $V_{g}$ yang bersesuaian dengan konduktansi beban tersebut juga ditampilkan pada Tabel 4. Titik pengendalian SEIG pada tegangan nominal 294 $\mathrm{V}$ merupakan nilai tegangan yang dijadikan sebagai titik acuan atau set-point $\left(V_{g, s p}\right)$.

Tabel 4. Titik pengendalian berupa masukan dan keluaran SEIG.

\begin{tabular}{|l|c|c|c|}
\hline \multirow{2}{*}{\multicolumn{1}{|c|}{ Besaran }} & \multicolumn{3}{c|}{ Nilai } \\
\cline { 2 - 4 } & Min & Nom & Maks \\
\hline Konduktansi beban SEIG $(\mu \mathrm{S})$ & 425 & 531 & 649 \\
Frekuensi $(\mathrm{Hz})$ & 49,5 & 50 & 50,5 \\
Tegangan SEIG $(\mathrm{V})$ & 280 & 294 & 306 \\
\hline
\end{tabular}

https://doi.org/10.25077/jnte.v9n3.802.2020

jnte.ft.unand.ac.id

\subsubsection{Identifikasi Waktu Tanggap Ideal}

Ketika jumlah beban SEIG berubah, keluaran SEIG dapat berada di luar rentang standar listrik. Agar keluaran SEIG selalu berada dalam rentang standar listrik Indonesia walaupun dalam keadaan peralihan, perlu diketahui waktu tanggap yang ideal bagi ELC untuk meregulasikan keluaran SEIG. Waktu tanggap ini diprediksi dari perubahan nilai $V_{g}$ terhadap waktu yang dimodelkan pada Persamaan (9), di mana $V_{g, \max }$ adalah tegangan maksimal SEIG yang mungkin dihasilkan $(360 \mathrm{~V})$, dan $V_{g, s p}$ adalah nilai tegangan nominal atau set point $(294 \mathrm{~V})$.

$$
\begin{aligned}
V_{g}(t)= & V_{g, \max } \\
& -\left(V_{g, \max }-V_{g, s p}\right) \cdot e^{\left(\frac{-t}{\tau_{g}}\right)}
\end{aligned}
$$

Dengan memasukkan nilai batas titik pengendalian SEIG sebesar $306 \mathrm{~V}$ sebagai nilai $V_{g}(t)$ serta konstanta waktu sebesar $376 \mathrm{~ms}$, didapatkan waktu tanggap ideal sebesar $76 \mathrm{~ms}$. Nilai $\tau_{g}$ sebesar $376 \mathrm{~ms}$ adalah konstanta waktu tersingkat pada pemberian masukan undak yang mengakibatkan keadaan tunak SEIG berada di luar standar, yaitu pada konduktansi beban $0 \mu \mathrm{S}$.

\subsection{Perancangan dan Identifikasi Komponen ELC}

Untuk dapat meregulasikan keluaran SEIG menuju titik pengendalian, disusun suatu ELC yang terdiri dari sensor, kontroler, dan aktuator. Sensor memberikan informasi mengenai keadaan SEIG, yang mana informasi tersebut dibutuhkan oleh kontroler untuk memberi masukan yang tepat pada aktuator. Aktuator kemudian mengubah keluaran SEIG sesuai masukan yang diberikan oleh kontroler.

\subsubsection{Perancangan dan Identifikasi Sensor}

Sensor yang dirancang adalah sensor tegangan dengan beberapa fungsi, yaitu penurunan tegangan $\mathrm{AC}$, filter band-pass, penyearahan tegangan $\mathrm{AC}$, filter ripple $\mathrm{DC}$, dan konversi nilai tegangan analog menjadi digital. Tegangan AC hingga $400 \mathrm{~V}$ dapat diturunkan dengan transformator penurun tergangan dengan rasio 220:12. Tegangan yang sudah diturunkan kemudian diminimalkan gangguan harmonisnya dengan filter band-pass pada rentang frekuensi $\left(f_{c}\right) 45 \mathrm{~Hz}$ hingga $55 \mathrm{~Hz}$. Filter tersebut tersusun dari pasangan nilai R-C sebesar $5 \mathrm{k} \Omega$ dan $578 \mathrm{nF}$ untuk filter high-pass, sementara untuk filter low- 
pass digunakan pasangan dengan nilai $15 \mathrm{k} \Omega$ dan $235 \mathrm{nF}$. Penentuan nilai ini didasarkan dari Persamaan (10). Selain itu, pasangan komponen berimpedans tinggi dipilih untuk mengurangi besar daya yang didisipasikan oleh sensor. Seluruh komponen resistor pada sensor memiliki daya disipasi maksimal sebesar $0,5 \mathrm{~W}$.

$$
f_{c}=\frac{1}{2 \pi R C}
$$

Setelah melalui filter band-pass, sinyal tegangan AC disearahkan dengan jembatan dioda 1N5408. Sinyal tegangan DC hasil keluaran jembatan dioda lalu diumpankan kepada filter ripple agar nilai yang dibaca oleh ADC lebih konstan. Kombinasi nilai RC pada filter ini bernilai $20 \mathrm{k} \Omega$ dan $85 \mu \mathrm{F}$. Agar kontroler Raspberry $\mathrm{Pi}$ dapat menerima data sinyal tegangan analog tersebut, digunakan IC ADC MCP3008 dengan protokol SPI. Rangkaian sensor yang dirancang ditampilkan pada Gambar $7 \mathrm{a}$, sementara bentuk fisik sensor tanpa transformator ditunjukkan pada Gambar 7b.

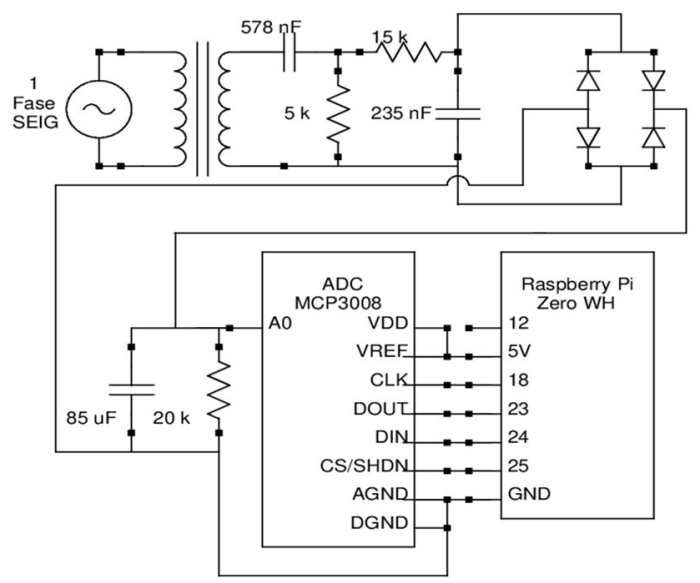

Gambar 7a. Rangkaian sensor pada ELC.

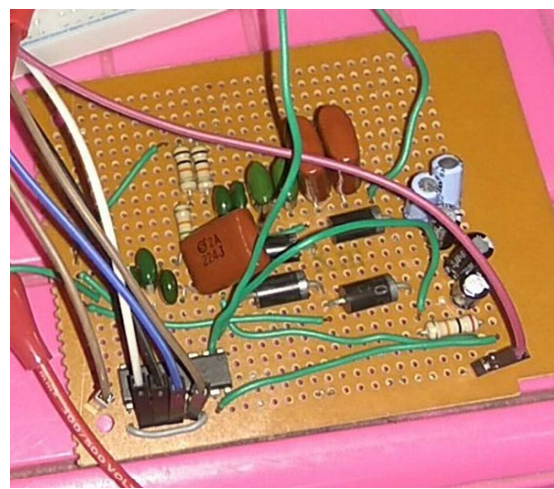

Gambar 7b. Bentuk fisik rangkaian sensor pada ELC tanpa transformator.
Sensor yang telah dirancang kemudian diimplementasikan dan diuji karakteristiknya. Korelasi tegangan AC masukan dari catu daya terhadap nilai digital keluaran sensor yang terbaca di Raspberry Pi ( $\left.V_{\text {dig }}\right)$ dirumuskan dalam Persamaan (11), dengan visualisasi grafis pada Gambar 8 .

$$
V_{\text {dig }}=2,747 V_{g}-65,147
$$

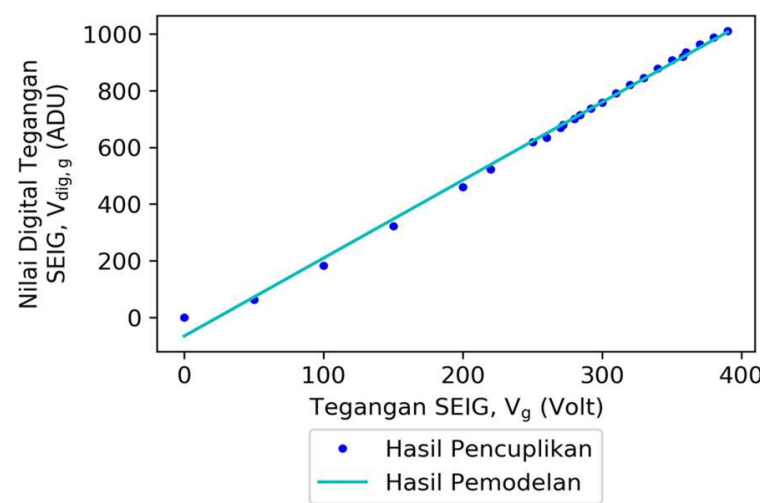

Gambar 8. Grafik korelasi $V_{g}$ terhadap $V_{\text {dig }}$.

Karakteristik tanggapan peralihan sensor diuji dengan memberikan masukan undak pada sensor dan mencuplik nilai tegangan $(V)$ beserta waktunya dengan Arduino. Hasil pencuplikan didekati dengan suatu model berbasis metode LS. Persamaan model berbasis metode LS yang diterapkan ditampilkan pada Persamaan (12) untuk pemberian undak naik, sementara untuk undak turun dirumuskan pada Persamaan (13). Hasil $\tau_{s}$ dari pemodelan tersebut dipaparkan pada Tabel 4. Nilai $\tau_{s}$ sebesar $1,852 \mathrm{~s}$ dipilih sebagai ekspektasi konstanta waktu sensor. Hasil pencuplikan dinormalisasi dengan Persamaan (8) agar lebih mudah dibandingkan dengan data lainnya. Sampel grafik tegangan yang dibaca sensor terhadap waktu ditampilkan pada Gambar $9 a$ dan $9 b$.

$$
\begin{gathered}
V(t)=V_{\text {akhir }} \cdot\left(1-e^{\frac{-t}{\tau_{s}}}\right) \\
V(t)=V_{\text {awal }} \cdot e^{\frac{-t}{\tau_{s}}}
\end{gathered}
$$

Tabel 5. Konstanta waktu peralihan sensor.

\begin{tabular}{|c|c|}
\hline Perubahan Undak $(\mathrm{V})$ & $\tau_{\mathrm{s}}(\mathrm{ms})$ \\
\hline $0 \rightarrow 220$ & 84 \\
$0 \rightarrow 400$ & 772 \\
$220 \rightarrow 0$ & 1.828 \\
$400 \rightarrow 0$ & 1.852 \\
\hline
\end{tabular}




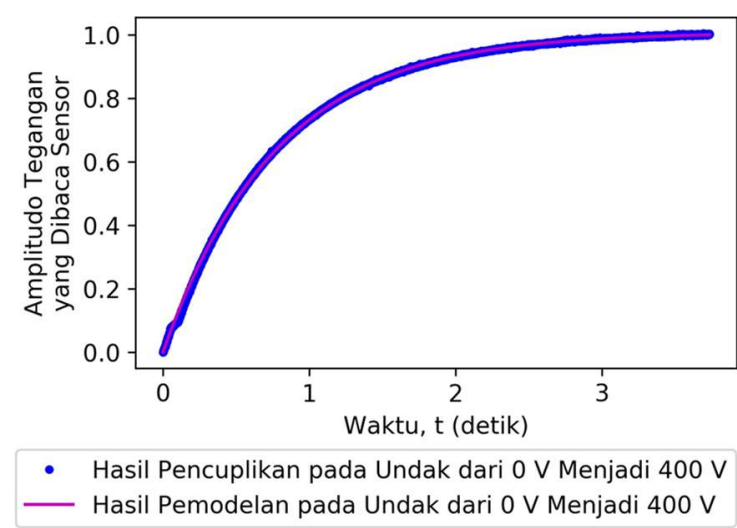

Gambar 9a. Grafik tanggapan peralihan sensor ketika mengalami perubahan tegangan masukan dari $0 \mathrm{~V}$ menjadi $400 \mathrm{~V}$.

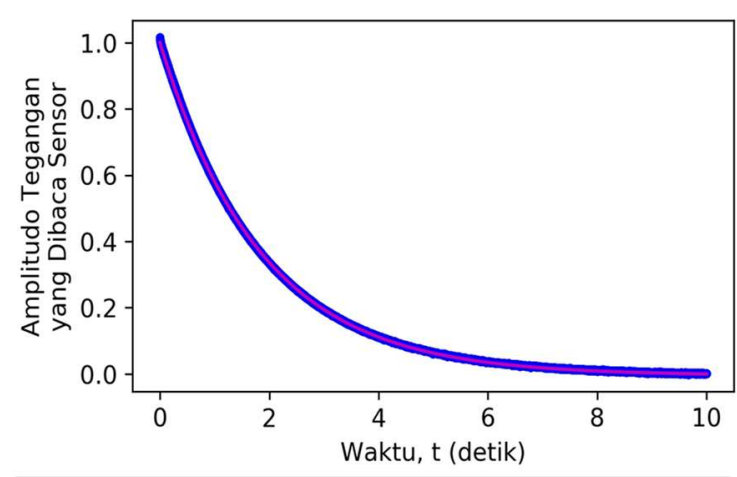

- Hasil Pencuplikan pada Undak dari $400 \mathrm{~V}$ Menjadi $0 \mathrm{~V}$ — Hasil Pemodelan pada Undak dari $400 \mathrm{~V}$ Menjadi $0 \mathrm{~V}$

Gambar 9b. Grafik tanggapan peralihan sensor ketika mengalami perubahan tegangan masukan dari $400 \mathrm{~V}$ menjadi $0 \mathrm{~V}$.

Karakteristik lain yang diuji adalah durasi konversi dan pembacaan sinyal tegangan analog menjadi digital dengan ADC. Pengujian dilakukan dengan mencuplik data durasi eksekusi pembacaan ADC untuk 7.122 sampel tanpa menyertakan outlier. Dari pengujian tersebut didapatkan data ekspektasi durasi berupa durasi maksimal sebesar $535 \mu \mathrm{s}$, dengan rerata durasi selama $449 \mu$ s.

\subsubsection{Perancangan dan Identifikasi Aktuator}

Aktuator yang dirancang tersusun dari penyearah tiga fase dengan dioda $1 \mathrm{~N} 5408$, beban palsu, rangkaian chopper dengan IGBT RJP63K2, dan driver optocoupler berbasis PC817. Penyearah tiga fase sekaligus dengan dioda dipilih karena memiliki kelebihan berupa kemudahan pengendalian karena hanya membutuhkan satu sinyal kendali dari kontroler.

Daya dari SEIG yang telah disearahkan diumpankan menuju ke rangkaian driver optocoupler dan beban palsu resistif $280 \Omega$ yang berspesifikasi daya disipasi maksimal $720 \mathrm{~W}$. Rangkaian driver optocoupler berfungsi untuk menyediakan tegangan yang cukup untuk mengoperasikan IGBT dengan sinyal PWM bertegangan rendah dari Raspberry Pi sebesar 3,3 $\mathrm{V}$. Resistor $82 \mathrm{k} \Omega$ pada driver berdaya disipasi maksimal $5 \mathrm{~W}$, sementara resistor lain berdaya disipasi maksimal 0,5 W. Dua dioda Zener berspesifikasi $V_{\text {Zener }}$ sebesar 4,6 V disusun seri untuk membatasi tegangan pada simpul yang terhubung dengan kolektor dari optocoupler. Batas nilai tegangan tersebut adalah dua kali nilai $V_{\text {Zener, yaitu }}$ 9,2 V. Nilai siklus kerja driver optocoupler dan IGBT $\left(k_{I G B T}\right)$ merupakan kebalikan dari nilai siklus kerja PWM dari Raspberry Pi $\left(k_{R P i}\right)$. Hubungan dari nilai siklus kerja PWM Raspberry Pi terhadap siklus kerja driver optocoupler dan IGBT dirumuskan dalam Persamaan (14). Nilai siklus kerja berada di antara 0 hingga 1 .

$$
k_{I G B T}=1-k_{R P i}
$$

Rangkaian beban palsu dan chopper IGBT bertindak sebagai pengatur besar beban efektif SEIG untuk mengompensasi perubahan keluaran SEIG akibat perubahan beban konsumen. Besarnya beban efektif $\left(G_{e f}\right)$ yang ditimbulkan rangkaian ini akibat masukan siklus kerja PWM dari driver optocoupler dirumuskan pada Persamaan (15). Persamaan (15) diturunkan dari Persamaan (3) dan digabungkan dengan hasil pengujian pengaruh nilai siklus kerja terhadap $V_{g}$. Nilai $k_{I G B T}$ berkisar dari 0 hingga 1 . Grafik korelasi dari siklus kerja driver optocoupler dan IGBT terhadap konduktansi beban efektif yang ditimbulkan ditampilkan pada Gambar 10.

$$
\begin{aligned}
G_{e f}= & -1,52 \cdot 10^{-3} k_{I G B T} \\
& +1,537 \cdot 10^{-3}
\end{aligned}
$$

Karakteristik peralihan rangkaian aktuator dianggap nol karena memiliki nilai yang sangat kecil, yaitu maksimal $18 \mu$ s untuk PC817 [14] dan 250 ns untuk IGBT RJP63K2 [15]. Rangkaian keseluruhan aktuator ditampilkan pada Gambar 11a, sementara bentuk fisik aktuator ditunjukkan pada Gambar $11 b$. 


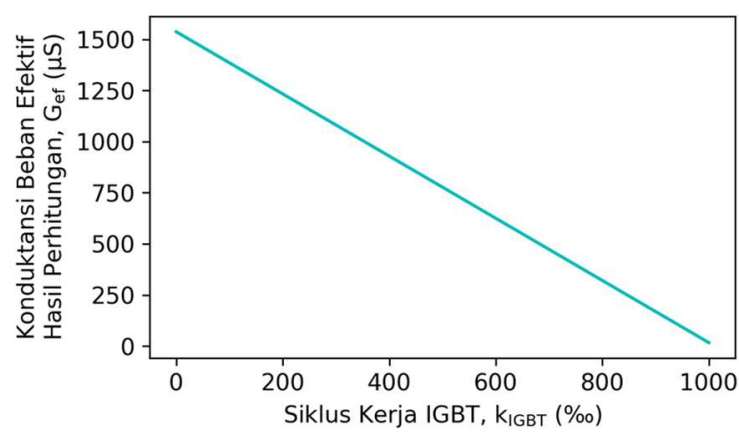

Gambar 10. Grafik korelasi siklus kerja IGBT terhadap konduktansi beban efektif SEIG.

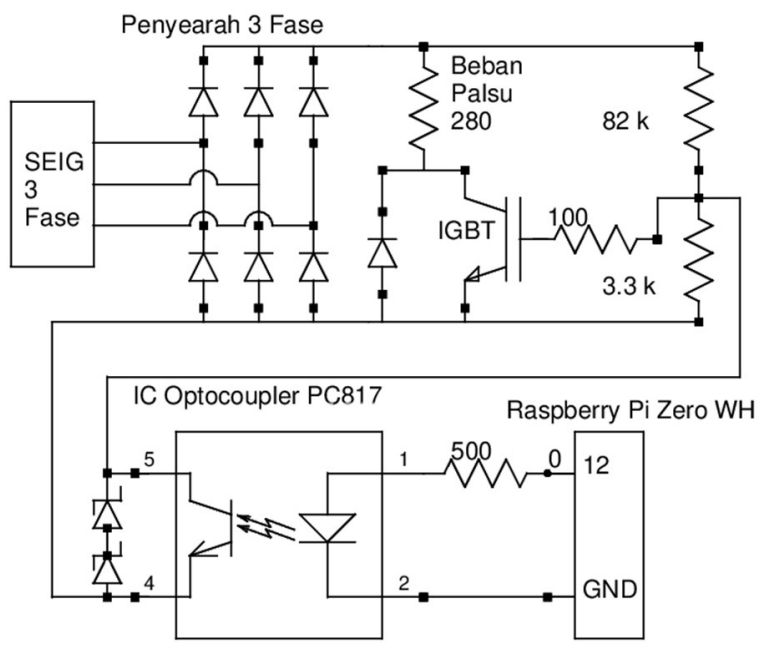

Gambar 11a. Rangkaian aktuator pada ELC [14].

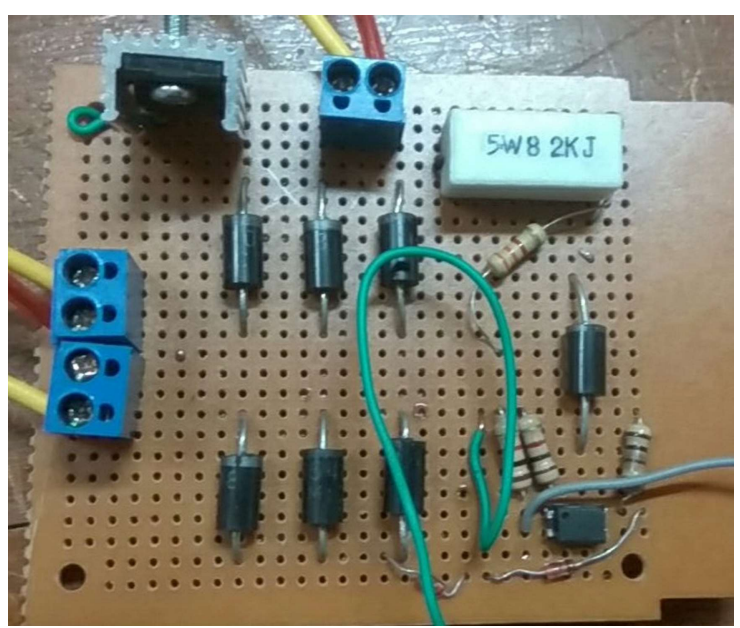

Gambar 11b. Bentuk fisik rangkaian aktuator dengan beban palsu belum terhubung [14].

\subsubsection{Perancangan dan Identifikasi Kontroler}

Raspberry Pi Zero WH digunakan untuk menerima masukan dari sensor dan memberikan keluaran variabel termanipulasi berupa siklus kerja PWM ke aktuator. Raspberry Pi disuplai dengan catu daya DC 5V 2A yang terpisah dari SEIG. Algoritma kontrol yang digunakan adalah Proportional-Integral (PI) berbasis bahasa pemrograman Python pada sistem operasi Raspbian.

Algoritma kontrol yang diterapkan dibagi dalam dua tahap, yaitu tahap setup atau penyusunan dan tahap kalang kontrol. Tahap penyusunan dieksekusi satu kali, dengan beberapa fungsi, yaitu penggunaan pustaka, pendefinisian langkah pembacaan ADC, pengaturan PWM hardware atau perangkat keras, dan pengaturan algoritma PI. Pustaka yang digunakan meliputi "time" untuk mengukur durasi eksekusi algoritma, "RPi.GPIO" untuk membaca data tegangan digital dari $\mathrm{ADC}$, dan "wiringpi" untuk menerapkan nilai siklus kerja PWM perangkat keras pada Raspberry Pi. Untuk menerima data tegangan melalui ADC, digunakan protokol SPI dengan pin-pin yang ditetapkan pada kode sumber. Nilai siklus kerja PWM perangkat keras diterapkan pada pin Raspberry Pi yang mendukung fungsi tersebut, dengan frekuensi dasar $2.342 \mathrm{~Hz}$ dan resolusi 0,001 atau 1 permil. Kendali PI diterapkan dengan beberapa variabel, yaitu nilai $K_{p}$ dan $K_{i}$ sebesar 5,0, batasan siklus kerja PWM dengan rentang $650 \%$ hingga $1000 \%$, serta titik acuan atau set-point tegangan digital sebesar 725 ADU. Nilai $K_{p}$ dan $K_{i}$ didapatkan dari penyeteman eksperimental.

Setelah algoritma penyusunan berbagai variabel kendali dieksekusi, kalang kontrol dijalankan secara terus-menerus. Kalang kontrol yang diterapkan terdiri dari empat fungsi. Fungsi pertama adalah perhitungan waktu yang telah berlalu dari eksekusi sebelumnya, yaitu $d t$. Fungsi selanjutnya adalah pembacaan tegangan digital dari ADC. Kemudian nilai keluaran siklus kerja PWM $\left(k_{R P i}\right)$ dihitung dengan algoritma PI yang disertai dengan anti integral windup. Algoritma PI yang digunakan dirumuskan pada Persamaan (16), di mana $k_{R P i}(t)$ masih dalam permil, sementara error e $(t)$ dalam satuan ADU. Adapun $e(t)$ dirumuskan pada Persamaan (17), yaitu berupa selisih nilai set-point tegangan digital 725 ADU dengan tegangan digital generator yang tercuplik $\left(V_{d i g, g}\right)$. Setelah nilai $k_{R P i}(t)$ didapat, nilai tersebut diterapkan pada Raspberry Pi sebagai PWM perangkat keras. 


$$
\begin{gathered}
k_{R P i}(t)=5 \cdot e(t)+ \\
5 \cdot \int_{0}^{t} e(t) \cdot d t \\
e(t)=725-V_{d i g, g}
\end{gathered}
$$

Untuk mengetahui ekspektasi durasi eksekusi dari kalang kontrol, dilakukan analisis hasil pencuplikan waktu eksekusi sejumlah kalang. Dari 17.596 sampel durasi tanpa outlier, didapatkan ekspektasi durasi terlama sebesar 4,19 $\mathrm{ms}$, dengan rerata durasi selama $1,23 \mathrm{~ms}$.

\subsection{Pengujian Kinerja ELC}

Sistem ELC-SEIG yang telah diimplementasikan kemudian diuji dengan perubahan undak beban untuk mengetahui kinerjanya [16]. Konduktansi beban tiga fase diubah dalam dua tahap singkat, di mana beban dua dari tiga fase diubah terlebih dahulu, sementara satu fase lainnya diubah setelahnya dengan jeda sesingkat mungkin. Besar undak konduktansi beban yang diterapkan untuk pengujian adalah sebesar $0 \mu \mathrm{S}, 465 \mu \mathrm{S}$, dan 530 $\mu \mathrm{S}$ untuk tiap fase. Pencuplikan data tegangan sesaat SEIG hasil pengujian dilakukan dengan rangkaian pada Gambar 1.

Terdapat tiga tolak ukur kinerja ELC yang ditetapkan, yaitu kemampuan ELC meregulasikan keluaran SEIG agar berada pada titik pengendalian, simpangan terjauh keluaran SEIG dari titik tegangan nominal $294 \mathrm{~V}$, dan durasi yang dibutuhkan agar keluaran SEIG kembali ke titik pengendalian semula setelah diberi perubahan masukan undak. Durasi tersebut dalam pembahasan ini disebut sebagai durasi pemulihan.

Hasil pengujian ELC-SEIG ditampilkan pada Gambar 12a untuk penurunan konduktansi beban, sementara untuk peningkatan konduktansi beban ditampilkan pada Gambar 12b. Pada kedua grafik disertakan garis bantu rentang dan titik pengendalian SEIG, yaitu ketika keluaran SEIG berada pada nilai minimal standar frekuensi sebesar 49,5 Hz, nilai nominal sebesar $50 \mathrm{~Hz}$, dan maksimal sebesar $50,5 \mathrm{~Hz}$. Ketiga nilai frekuensi tersebut bersesuaian dengan nilai tegangan 280 V, $294 \mathrm{~V}$, serta $306 \mathrm{~V}$ secara berurutan. Nilainilai penting terkait tolak ukur kinerja ELC dari hasil pengujian dipaparkan pada Tabel 6. Dari hasil pengujian tersebut, diketahui bahwa durasi pemulihan SEIG sebanding dengan besar perubahan undak konduktansi beban, dengan nilai terlama $832 \mathrm{~ms}$. Selain itu, pada umumnya durasi pemulihan pada penurunan konduktansi beban lebih singkat daripada saat peningkatan konduktansi beban. Pada perubahan konduktansi beban di antara $465 \mu \mathrm{S}$ dan $530 \mu \mathrm{S}$, SEIG telah pulih ke kondisi semula pada perubahan konduktansi tahap pertama, sehingga nilai tersebut yang dijadikan sebagai acuan durasi pemulihan.

Kinerja ELC berupa simpangan terjauh tegangan dan frekuensi dari nilai nominalnya secara umum sebanding dengan besar perubahan konduktansi beban. Simpangan terjauh tegangan dicapai pada peningkatan konduktansi beban dari $0 \mu \mathrm{S}$ ke $530 \mu \mathrm{S}$, yaitu sejumlah $-12,24 \%$ atau -36 $\mathrm{V}$ dari nilai nominalnya. Sementara itu, simpangan terjauh frekuensi dicapai ketika penurunan konduktansi beban dari $465 \mu \mathrm{S}$ ke 0 $\mu \mathrm{S}$, yaitu sebesar $+3,2 \%$ atau $+1,6 \mathrm{~Hz}$ dari nilai nominalnya. Nilai frekuensi ini didapat dari konversi $V_{g}$ dengan Persamaan (5). Selain itu, disimpulkan juga bahwa simpangan tegangan akan lebih dominan pada peningkatan konduktansi beban, sedangkan simpangan frekuensi akan lebih dominan pada penurunan konduktansi beban SEIG.

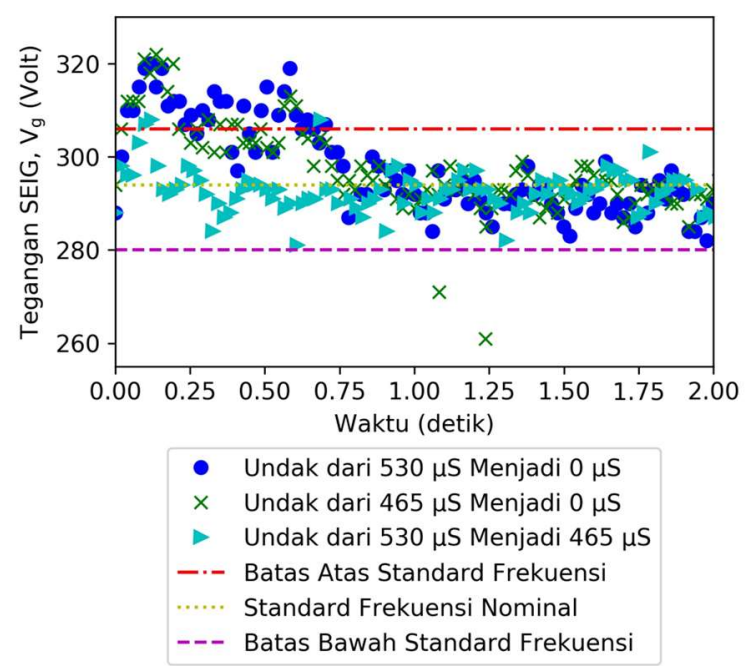

Gambar 12a. Grafik $V_{g}$ pada uji kinerja ELC dengan penurunan konduktansi beban. 


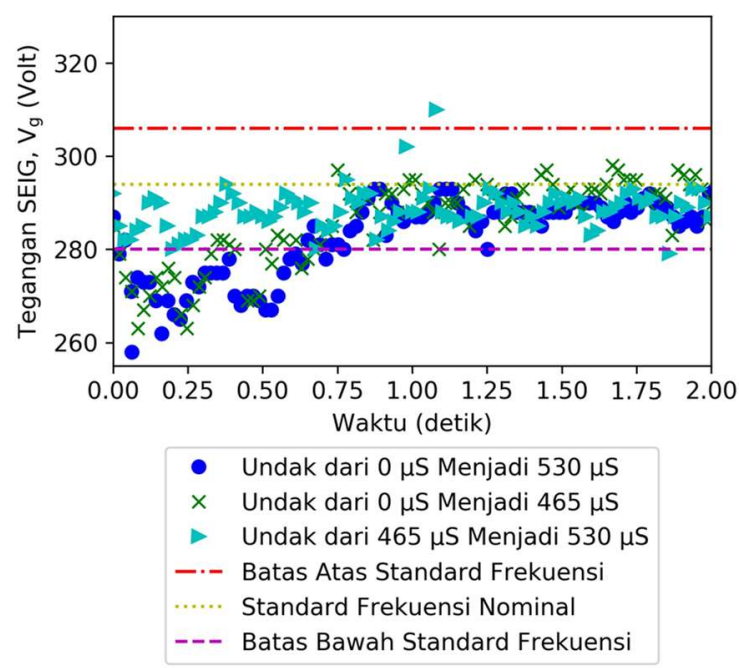

Gambar 12b.Grafik $V_{g}$ pada uji kinerja ELC dengan peningkatan konduktansi beban.

Tabel 6. Hasil uji kinerja ELC dalam meregulasikan SEIG.

\begin{tabular}{|c|c|c|c|}
\hline $\begin{array}{c}\text { Perubahan } \\
\text { Undak } \\
(\mu \mathrm{S})\end{array}$ & $\begin{array}{c}\text { Simpangan } \\
\text { Tegangan } \\
\text { Maksimal }(\%)\end{array}$ & $\begin{array}{c}\text { Simpangan } \\
\text { Frekuensi } \\
\text { Maksimal }(\%)\end{array}$ & $\begin{array}{c}\text { Durasi } \\
\text { Pemulihan } \\
(\mathrm{ms})\end{array}$ \\
\hline $465 \rightarrow 530$ & $-4,76$ & $-1,0$ & $361^{*}$ \\
$0 \rightarrow 465$ & $-10,54$ & $-2,2$ & 732 \\
$0 \rightarrow 530$ & $-12,24$ & $-2,6$ & 832 \\
$530 \rightarrow 465$ & 4,76 & 1,6 & $143^{*}$ \\
$465 \rightarrow 0$ & 9,52 & 3,2 & 723 \\
$530 \rightarrow 0$ & 8,84 & 2,8 & 760 \\
\hline
\end{tabular}

* Pemberian undak tahap pertama

\section{Kesimpulan}

Sistem ELC berbasis Raspberry Pi yang dapat meregulasikan keluaran SEIG agar sesuai dengan standar frekuensi kelistrikan Indonesia telah dirancang. Susunan ELC tersebut terdiri dari sensor tegangan, aktuator, dan kontroler Raspberry Pi Zero WH. Komponen sensor terdiri dari transformator, filter band-pass, penyearah jembatan dioda, filter ripple, dan ADC. Sementara itu, komponen aktuator terdiri dari penyearah tiga fase dengan dioda, beban palsu, driver optocoupler, dan IGBT. Kontrol yang diterapkan adalah PI berbasis bahasa pemrograman Python, dengan nilai $K_{p}$ dan $K_{i}$ hasil penyeteman eksperimental sebesar 5,0. Rancangan ELC telah dapat meregulasikan SEIG dalam keadaan tunaknya sesuai standar frekuensi listrik Indonesia.

\section{Daftar Pustaka}

[1] N. Winanti, B. Halimi, A. Purwadi and N. Heryana, "Study and Design of EnergySaving Solar Lamp for Rural Area in Indonesia," 2018 2nd International Conference on Green Energy and Applications (ICGEA), Singapore, 2018, pp. 98-102. doi:10.1109/

ICGEA.2018.8356307.

[2]

M. Taoufik, B. Abdelhamid and S. Lassad, "Stand-alone self-excited induction generator driven by a wind turbine," Alexandria Eng. J., vol. 57, pp 781-786, Feb. 2017, doi: 10.1016/ j.aej.2017.01.009.

[3] R. R. Singh, B. A. Kumar, D. Shruthi, R. Panda and C. T. Raj, "Review and experimental illustrations of electronic load controller used in standalone MicroHydro generating plants," Eng. Sci. and Technol., an Int. J., vol. 21, pp. 886-900, Jul. 2018, doi: 10.1016/

j. Jestch.2018.07.006.

[4] A. Zoitl, T. Strasser and G. Ebenhofer, "Developing modular reusable IEC 61499 control applications with 4DIAC," 2013 11th IEEE International Conference on Industrial Informatics (INDIN), Bochum, 2013, pp. 358-363. doi: 10.1109/INDIN.2013.6622910.

[5] Eclipse Found.. "Where to Start 4DIAC." eclipse.org.

https://www.eclipse.org/4diac/ en help.php?helppage $=\mathrm{html} /$ startHere/startHere.html (accessed May 17, 2020).

[6] D. Raja. "Raspberry Pi PWM Tutorial.". circuitdigest.com.

https://circuitdigest.com/microcontroller -projects/raspberry-pi-pwm-tutorial (accessed Jun 23, 2020).

[7] B. Singh, S. S. Murthy and S. Gupta, "Transient analysis of self-excited induction Generator with electronic load controller (ELC) supplying static and dynamic loads," in IEEE Transactions on Industry Applications, vol. 41, no. 5, pp. 
1194-1204, Sept.-Oct. 2005. doi: 10.1109/TIA.2005.855047.

[8] The Document Found., Germany. Trend Lines, v6.4. (2017). Accessed: July 1, 2020. [Online]. Available: https:// help.libreoffice.org/6.4/en-US/text/ schart/01/04050100.html?DbPAR= CHART\#bm id1744743

[9] Gurley. (2009). Numerical Methods Lecture 5 - Curve Fitting Techniques [Lecture Note]. Available: http:// web.iitd.ac.in/ pmvs/courses/mel705/ curvefitting.pdf

[10] S. J. Miller. (2006). The Method of Least Squares [Lecture Paper]. Available: https://web.williams.edu/

Mathematics/sjmiller/public html/

BrownClasses/54/handouts/

MethodLeastSquares.pdf

[11] D.C. Harris, "Nonlinear Least-Squares Curve Fitting with Microsoft Excel Solver," (J. of Chem. Educ.) Journal of Chemical Education, vol. 75, no. 1, pp. 119-121, Jan. 1998.

[12] M. M. S. Alvarez, D.T. Pham, M. Y. Prostov, dan Y. I. Prostov, "Statistical approach to normalization of feature vectors and clustering of mixed datasets," in Proc. The Royal Society A, 2012, pp. 2630-2651, doi:10.1098/ rspa.2011.0704.

[13] Aturan Distribusi Tenaga Listrik, Peraturan Menteri Energi dan Sumber Daya Mineral No. 04 Tahun 2009, Feb. 2009. [Online]. Available:

https://jdih.esdm.go.id/peraturan/permen -esdm-04-2009.pdf

[14] Sharp Corp., PC817X Series, D2A03101EN. (2003). [Online]. Available: https://www.farnell.com/datasheets/ 73758.pdf

[15] Renesas Electron. Corp., RJP63K2DPPM0 Preliminary Datasheet, Revision 2. (2011). [Online]. Available:

https://www.renesas.com/sg/en/doc/prod ucts/transistor/002/

r07ds0468ej_rjp63k2dpp.pdf

[16] I. N. Hakim, "Desain Pengendali Beban Elektronis untuk Generator Induksi Terisolasi Berbasis Penyearah Tiga Fase Menggunakan Raspberry Pi," S.T. thesis, Departemen Teknik Nuklir dan Teknik Fisika, Universitas Gadjah Mada, Yogyakarta, Indonesia, 2020.

\section{Biodata Penulis}

Ihsan Nur Hakim, menempuh studi S1 di Teknik Fisika Universitas Gadjah Mada. Bidang riset yang diminati mencakup sistem energi terbarukan dan multifisika.

Aan Listanto Amdrian, menempuh studi S1 di Teknik Fisika Universitas Gadjah Mada. Bidang riset yang diminati mencakup sistem energi terbarukan.

Adlan Bagus Pradana, mendapat gelar M.Tech. dari Indian Institute of Technology Delhi. Saat ini berprofesi sebagai dosen di Departemen Teknik Elektro dan Informatika, Sekolah Vokasi, Universitas Gadjah Mada. Bidang riset yang ditekuni adalah elektronika daya, mesin listrik, dan energi terbarukan.

Awang Noor Indra Wardana, mendapat gelar Doktor dari Universität Kassel. Saat ini berprofesi sebagai dosen di Departemen Teknik Nuklir dan Teknik Fisika, Universitas Gadjah Mada, Yogyakarta. Bidang riset yang ditekuni adalah otomasi proses, pengembangan sistem, dan sistem terintegrasi. 